\title{
Papillary carcinoma thyroid - A cytomorphological study
}

\author{
Bhat $\mathrm{A}^{1}$, Varma $\mathrm{L}^{1}$, Fernandes $\mathrm{H}^{1}$, Jayaprakash $\mathrm{CS}^{1}$ \\ ${ }^{I}$ Department of pathology, Father Muller Medical College, Mangalore, India
}

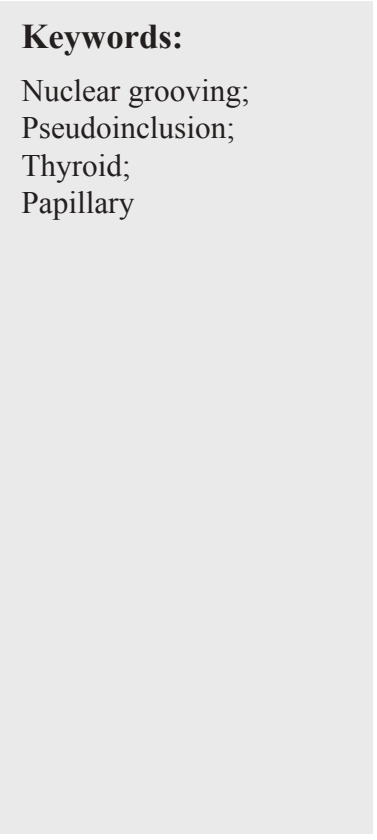

\begin{abstract}
Background: Fine Needle Aspiration Cytology is a widely accepted diagnostic tool for thyroid lesions. It is well known that nuclear features form the mainstay of diagnosis for papillary carcinoma thyroid. Focal nuclear features can be missed unless carefully looked for and pose diagnostic difficulty. The aim was to study the cytomorphological features of papillary carcinoma thyroid and to calculate the percentage of nuclear grooving.
\end{abstract}

Materials and Methods: This retrospective study was carried out by reviewing the data and cytology smears of 21 histopathologically confirmed cases of papillary carcinoma thyroid. The percentage of nuclear grooves was calculated in oil immersion by counting 200 to 500 cells depending on the cellularity. The study was approved by the institution ethical and research committee.

Results: Out of the total 21 cases, 03(14.2\%) were males and 18(83.8\%) were females. Mean age was 38.9 years. Predominant papillary arrangement was seen in $17(80.9 \%)$ of the cases. Nuclear crowding and overlapping, pale chromatin,nuclear grooves, nuclear enlargement and prominent nucleoli were seen in all (100\%) the cases. Intranuclear cytoplasmic pseudoinclusions were seen in only $5(23.8 \%)$ of the cases. The percentage of nuclear grooving ranged from $15 \%$ to $85 \%$. Greater than $20 \%$ nuclear grooves were observed in $19(90.4 \%)$ of the cases. Histiocytes, metaplastic cells and multinucleated giant cells were seen in $12(57.1 \%), 10(47.6 \%)$ and $6(28.5 \%)$ of the cases.

Conclusion: The cytologic diagnosis of papillary carcinoma is easy when majority of the classical features are present. But it becomes really challenging when the features are either present focally or classical features are absent.

\section{INTRODUCTION}

Fine Needle Aspiration Cytology is a widely accepted diagnostic tool for thyroid lesions. It is well known that nuclear features form the mainstay of diagnosis

\section{Correspondence:}

Dr. Archana Bhat, MBBS, MD

Assistant Professor, Department of pathology,

Father Muller Medical College, Mangalore, India

Email : archibhat3@gmail.com for papillary carcinoma thyroid. The classical features of papillary carcinoma include enlarged, overlapping nuclei with powdery chromatin, intranuclear cytoplasmic pseudoinclusions and nuclear grooves. ${ }^{1}$ Focal nuclear features are associated more commonly with follicular variant of papillary carcinoma thyroid. ${ }^{2}$ Focal nuclear features can be missed unless carefully looked for and pose diagnostic difficulty. The aim of this study was to study the cytomorphological features of papillary carcinoma thyroid 
and to calculate the percentage of nuclear grooving.

\section{MATERIALS AND METHODS}

This retrospective study was carried out in the Department of Pathology, Father Muller Medical College during a 2 year period from September 2013 to September 2015. Study was conducted after acquiring permission from ethical review committed. The study was approved by the institution ethical and research committee. The data and cytology smears of 21 histopathologically confirmed cases of papillary carcinoma thyroid were reviewed and the following data- age, gender distribution, cellular arrangement, nuclear features, colloid, histiocytes, metaplastic cells, were analysed. The nuclear size was compared to that of $\mathrm{RBC}$ and greater than twice the size of RBC was considered nucleomegaly. The percentage of nuclear grooves was calculated in oil immersion by counting 200 to 500 cells depending on the cellularity. Statistical analysis was performed using Excel and frequencies were calculated.

\section{RESULTS}

A total of 21 histopathologically confirmed cases of papillary carcinoma were studied. The age at presentation ranged from 17 years to 65 years with the mean age being 38.9 years. A female predominance was observed with $03(14.2 \%)$ males and $18(83.8 \%)$ females. Predominant papillary arrangement was seen in 17(80.9\%). Nuclear crowding and overlapping, pale chromatin, nuclear grooves, nuclear enlargement and prominent nucleoli were seen in all(100\%) the cases. Intranuclear cytoplasmic pseudoinclusions were seen in only $5(23.8 \%)$ of the cases. Histiocytes, metaplastic cells and multinucleated giant cells were seen in $12(57.1 \%)$, $10(47.6 \%)$ and $6(28.5 \%)$ of the cases respectively. The percentage of nuclear grooving ranged from $15 \%$ to $85 \%$. Greater than $20 \%$ nuclear grooves were observed in $19(90.4 \%)$ of the cases.

\section{DISCUSSION}

FNAC is a widely accepted and reliable test in the diagnosis of papillary carcinoma thyroid. Various studies have shown a very high sensitivity and specificity. A sensitivity greater than $90 \%$ is demonstrated by several studies. ${ }^{3-5}$ Chen et $\mathrm{al}^{6}$ showed that FNAC can be solely relied upon in diagnosis of papillary carcinoma thyroid to warrant surgical resection with a specificity as high as 98 percent.

The cytologic diagnosis of papillary carcinoma thyroid is difficult when the classical features are absent or focally present. The diagnostic features of papillary carcinoma as described by Kini et $\mathrm{al}^{7}$ included papillary tissue fragments, monolayered sheets, syncytial tissue fragments, intranuclear cytoplasmic inclusions, psammoma bodies and multinucleated giant cells. Later $\mathrm{Koss}^{8}$ suggested that cytological features of papillary carcinoma thyroid were cellular rich aspirates with little colloid, sharply outlined papillary clusters, distinct cytoplasmic borders, enlarged nuclei, nucleoli, intranuclear cytoplasmic inclusions and psammoma bodies. Rupp et $\mathrm{al}^{9}$ emphasized the importance of nuclear grooves in the cytodiagnosis of papillary carcinoma thyroid. Lowhagen first described "ropy colloid" in FNA smears of papillary carcinoma thyroid.

DeMay ${ }^{11}$ described 13 criteria by dividing them into 4 groups as follows:

A. Architectural- 3 dimensional papillae with cores, 3 dimensional caps without cores, 2 dimensional sheets with fingers

B. Cytoplasmic - squamoid features, septate vacuoles

C. Nuclear- grooves, marginated nucleoli, pale chromatin, intranuclear cytoplasmic inclusions

D. Background - gummy colloid, epitheloid giant cells, psammoma bodies.

Cellular swirls were studied and described by Arnold et a ${ }^{12}$ and they suggested that this feature is specific for papillary carcinoma thyroid, though the sample size was small. Intranuclear cytoplasmic pseudoinclusions are specific but are present frequently in only a few number of cases.

Nuclear grooves are one feature observed to be more consistently associated with papillary carcinoma thyroid. However nuclear grooves can be seen in other thyroid lesions like hashimotos thyroiditis, colloid goiter, adenomatous hyperplasia and follicular lesions. When to consider nuclear grooves as significant is a diagnostic dilemma. Various authors have evaluated the percentage of cells showing nuclear grooves and given their results. In a study by Yang et $\mathrm{al}^{13}$, the specificity and sensitivity of nuclear grooves for papillary carcinoma at $>=20 \%$ were $95 \%$ and $65 \%$ respectively and those at $>=10 \%$ were $68 \%$ and $100 \%$ respectively. In a study by Francis et a $1{ }^{14}$ nuclear grooves at $>=20 \%$ were seen in $88 \%$ of the total cases, $(n=34)$.

Another issue is interpretation of FNA smears of nodules arising in a background of thyroid diseases. These cells from a nodule arising in a background of Graves disease exhibit significant nuclear atypia in the form of nuclear enlargement with hyperchromasia or nuclear clearing. Therefore it is wise to make diagnosis of papillary carcinoma diagnosis in nodule arising in a background of Graves disease only when all other features are also present. ${ }^{15}$ In cases of papillary carcinoma arising in a background of Hashimotos thyroiditis the diagnosis becomes difficult because of the overlapping features. Presence of two types of cellular proliferations are seen. One is composed of tumour fragments with features of 
papillary carcinoma and without infiltrating lymphocytes. While the other is composed of reactive cell groups or hurthe cells with some atypia, infiltration of lymphocytes but without other features of papillary carcinoma. ${ }^{16}$ Apart from these there are various technical factors like staining, sampling, air drying etc which add to the difficulties in tnterpretation.

Papillary carcinoma is known for its varied cytologic features. In a given case all the features are not present always. When present in combination and diffusely, it is very easy to render a confident cytologic diagnosis. But most of the times the features are focal making it a tuff task. A study by Renshaw et $\mathrm{al}^{17}$ showed that presence of focal features (less than 20 cells with features) of papillary carcinoma are strongly associated with papillary carcinoma at resection. This study suggests that surgical resection for cases even with focal cytological features is justified.

\section{CONCLUSION}

The cytologic diagnosis of papillary carcinoma is easy when majority of the classical features are present. But it becomes really challenging when the features are either present focally or classical features are absent. It is worth the effort to carefully look for focal and subtle features as these can be easily missed.

\section{REFERENCES}

1. Andrew A, Renshaw MD. Focal Features of Papillary Carcinoma of the Thyroid in Fine-Needle Aspiration Material Are Strongly Associated With Papillary Carcinoma at Resection. Am J Clin Pathol. 2002;118:208-10. Crossref

2. Logani S, Gupta PK, LiVolsi VA, et al. Thyroid nodules with FNA cytology suspicious for follicular variant of papillary thyroid carcinoma: follow-up and management. Diagn Cytopathol. 2000;23:380-5. Crossref

3. Gharib H, Goellner JR, Johnson DA. Fine-needle aspiration cytology of the thyroid. A 12-year experience with 11,000 biopsies. Clin Lab Med 1993;13:699-709. Crossref

4. Gharib H, Goellner JR. Fine-needle aspiration biopsy of the thyroid: an appraisal. Ann Intern Med 1993;118:282-9. Crossref

5. Tielens ET, Sherman SI, Hruban RH, Ladenson PW. Follicular variant of papillary thyroid carcinoma. A clinicopathologic study. Cancer 1994;73:424-31. Crossref

6. Chen H, Zeiger MA, Clark DP, Westra WH, Udelsman R. Papillary carcinoma of the thyroid: can operative management be based solely on fine-needle aspiration? J Am Coll Surg 1997;184:605-10. Crossref
7. Kini SR, Miller JM, Hamburger JI et al. Cytopathology of papillary carcinoma of the thyroid by fine needle aspiration. Acta Cytol1980;24:511-21. Crossref

8. Koss LG, Woyke S, Olszewski W. Aspiration biopsy: cytologic interpretation and histologic bases. Igaku- Shoin Medical Publishers, Inc.: New York, 1984, pp 169-70.

9. Rupp M, Ehya H. Nuclear grooves in the aspiration cytology of papillary carcinoma of the thyroid. Acta Cytol 1989;33:216. Crossref

10. Lowhagen T, Willems JS, Lundell G et al. Aspiration biopsy cytology in diagnosis of thyroid cancer. World J Surg 1981;5:61-73. Crossref

11. DeMay RM. The art and science of cytopathology. American Society of Clinical Pathologists: Chicago, 1996, pp 730-4.

12. Szporn AH, Yuan S, Wu M, Burstein DE. Cellular swirls in fine needle aspirates of papillary thyroid carcinoma: a new diagnostic criterion. Mod Pathol. 2006;19:1470-3. Crossref

13. Yang YJ, Demirci SS. Evaluating the diagnostic significance of nuclear grooves in thyroid fine needle aspirates with a semiquantitative approach. Acta Cytol. 2003;47:563-70. Crossref

14. Francis IM, Das DK, Sheikh ZA, Sharma PN, Gupta SK. Role of nuclear grooves in the diagnosis of papillary thyroid carcinoma. A quantitative assessment on fine needle aspiration smears. Acta Cytol. 1995;39:409-15. Crossref

15. Anderson SR, Mandel S, LiVolsi VA, et al. Can cytomorphology differentiate between benign nodules and tumors arising in Graves' disease? Diagn Cytopathol. 2004;31:64-7. Crossref

16. Baloch Z, LiVolsi VA. Diagnostic dilemmas in thyroid pathology: follicular variant of papillary thyroid carcinoma and classic papillary thyroid carcinoma arising in lymphocytic thyroiditis. Pathol Case Rev. 2003;8:47-56. Crossref

17. Renshaw AA. Focal Features of Papillary Carcinoma of the Thyroid in Fine-Needle Aspiration Material Are Strongly Associated With Papillary Carcinoma at Resection. Am J Clin Pathol. 2002;118:208-10. Crossref 